\title{
Facile and Green Synthesis of $\alpha, \beta$-Unsaturated Ketone Catalyzed by Air-Stable Organobismuth Complex
}

\author{
Renhua Qiu ${ }^{1}$, Yimiao Qiu ${ }^{1}$, Zhengong Meng ${ }^{1}$, Xingxing Song ${ }^{1}$, Zhenyong Jia ${ }^{1}$, Kun $\mathrm{Yu}^{1}$, Shuangfeng Yin ${ }^{1}$, \\ Chak-Tong Au ${ }^{2}$, Wai-Yeung Wong ${ }^{2}$ \\ ${ }^{1}$ Collenge of Chemistry and Chemical Engineering, Hunan University, Changsha, P.R. China \\ ${ }^{2}$ Department of Chemistry, Hong Kong Baptist Universtiy, Hong Kong, China \\ Email: sf yin@hnu.edu.cn, pctau@hkbu.edu.hk, rwywong@hkbu.edu.hk
}

Received 2012

\begin{abstract}
Air-stable cationic organobismuth complexes (2-5) possessing both acidic and basic characters were synthesized. The catalyst system that comprises an air-stable bifunctional Lewis acidic/basic organobismuth complex and $\left[\mathrm{Bmim}^{\mathrm{B}} \mathrm{BF}_{4}\right.$ showed high catalytic activity, diastereoselec-tivity, stability, and reusability in the one-pot synthesis of $(E)$ - $\alpha, \beta$-unsaturat-ed ketones through highly selective crossed-condensation of ketones and aldehydes. Through switching the reaction from homogeneous to heterogeneous, the system shows facile separation ability and facile reusability.
\end{abstract}

Keywords: $\alpha, \beta$-Unsaturated Ketone; Catalysis; Facile Seperation Catalytic System;Organobismuth; .Synthesis

\section{Introduction}

$\alpha, \beta$-Unsaturated carbonyl compounds are widely used as substrates for a number of reactions such as hydrogenation, epoxidation, peroxidation, cycloaddition, and conjugate addition. Aldol condensation reaction of carbonyl compounds is the most common processfor the synthesis of $\alpha, \beta$-unsaturated carbonyl compounds. Claisen-Schmidt condensation, a crossed aldol condensation of an aromatic aldehyde and an aliphatic ketone or aldehyde under basic conditions, is traditionally used process. In the reaction, a relatively strong base (such as metal hydroxide or metal alkoxide) is employed, and selective mono-condensation is often difficult due to side reactions such as bis-condensation and aliphatic aldehyde dimerization. Application of the method is further limited because substrates with base-sensitive functional groups are not suitable. A better approach is by means of the Mukaiyama-aldol reaction followed by subsequent dehydration catalyzed by a Lewis acid. Recently, Yanagisawa et al. reported the one-pot selective synthesis of $\alpha, \beta$-unsaturated ketones from alkenyl trichloroacetates and aldehydes; in this approach, ketones have to be converted to alkenyl trichloroacetates before the condensation reaction.

Catalytic direct crossed-condensation of ketones and aldehydes would be an ideal process for the synthesis of $\alpha, \beta$-unsaturated carbonyl compounds, because there is no need to prepare reactive intermediates (e.g. silyl enol ether) and only $\mathrm{H}_{2} \mathrm{O}$ is generated as a side-product (Scheme 1). Such a process is significantly "energy-efficient" and "atom economic" since multistep transformations and separation of product (from by-products) is not necessary. Recently, use of organocatalysts for direct crossed-condensation reaction was reported, while high catalyst loading is necessary (20 $\mathrm{mol} \%$ ).

We are interested in the study of organobismuth complexes because bismuth is a stable (green) heavy element. The utilization of bismuth compounds in the field of catalysis and organic synthesis has been studied intensively in recent years. Simple bismuth Lewis acids such as bismuth halides and triflates are catalysts highly efficient in a number of reactions. The use of designed cationic organobismuth compounds in catalysis, however, is rarely reported partly due to the instability of the Bi-C bond. In this paper, air-stable cationic organobismuth com-

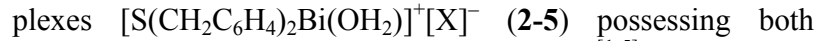
acidic and basic characters are synthesized ${ }^{[1-5]}$ Furthermore, we herein report a catalytic process that is based on the facile separation approach. The catalyst system is composed of an airstable Lewis acidic/basic bifunctional complex $\left[\mathrm{S}\left(\mathrm{CH}_{2} \mathrm{C}_{6} \mathrm{H}_{4}\right)_{2} \mathrm{Bi}\right.$ $\left.\left(\mathrm{OH}_{2}\right)\right]^{+}\left[\mathrm{BF}_{4}\right]^{-}$(1) and $[\mathrm{Bmim}] \mathrm{BF}_{4}$ (1-buty-3-methylimidazolium tetrafluoroborate); it shows high catalytic efficiency for the green synthesis of $(E)-\alpha, \beta$-unsaturated ketones through cross-condensation of aldehydes and ketones.

\section{Results and Discussion}

Shown in Scheme 2 is the synthetic route of the organobismuth complexes 1-5. Treatment of $\left.\mathrm{S}_{(} \mathrm{CH}_{2} \mathrm{C}_{6} \mathrm{H}_{4}\right)_{2} \mathrm{BiCl} 1$ with $\mathrm{AgX}$ in THF afforded organobismuth complexes 2-5 quantitatively. The results of ${ }^{1} \mathrm{H}$ NMR spectroscopy and elemental analysis show

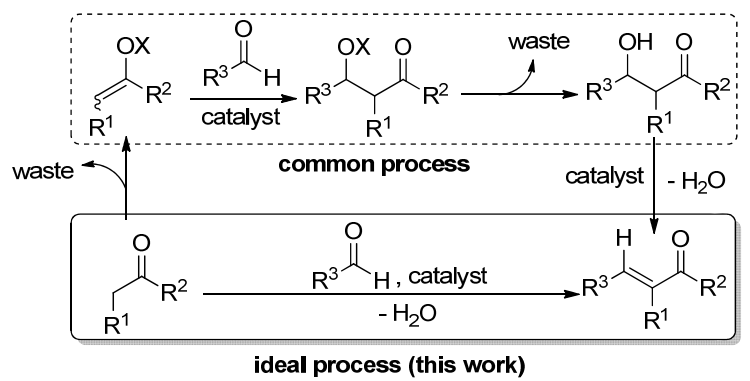

Scheme 1. A comparison between a common process and an ideal process for the selective synthesis of $\alpha, \beta$-unsaturated ketones. 
that samples 2-5 freshly obtained from recrystallization contain one water molecule. They are air-stable and show good water tolerance. They remained as dry colorless crystals or white powder in ambient environment in a test period of one year.

The thermal behavior of complexes 2-5 was investigated by TG-DSC in $\mathrm{N}_{2}$ (Figure 1). The materials show high thermal stability, especially complexes $\mathbf{4}$ and $\mathbf{5}$ with perfluoroalkylsulfonate counter anions (stable up to $230^{\circ} \mathrm{C}$ ). We also employed the Hammett indicator method ${ }^{11 a-b}$ to determine acidity and basicity, and found moderate acidity with acid strength of $3.3<$ $H_{o} \leq 4.8$ for 3-5 and $4.8<H_{o} \leq 6.8$ for 2 . In terms of basicity, the four complexes exhibit strength of $7.2 \leq H_{-}<8.9$. It is worth pointing out that complex 1 shows no acidity but basicity $\left(7.2 \leq H_{-}<8.9\right.$.). Despite Lewis acid/base pair exists in complexes $\mathbf{2 - 5}$, there is no sign of self-quenching. With the steric effect of the butterfly-shaped ligand structure and the presence of bismuth-sulfur bifunctional centers, it is envisaged that complexes 2-5 are efficient and stereoselective catalysts.

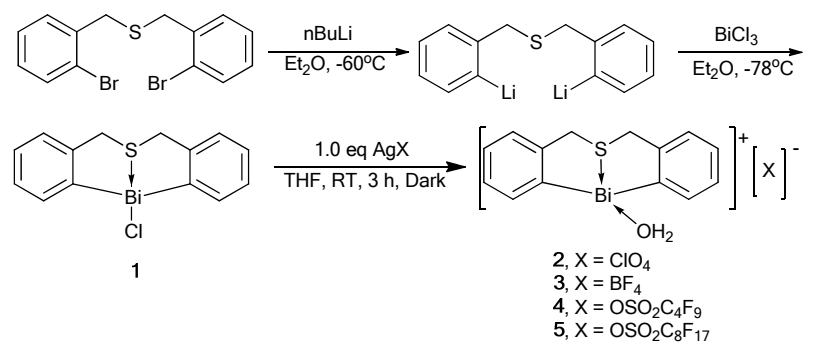

Scheme 2. Synthetic routes of butterfly-shaped sulfur-bridged organobismuth complexes 1-5.

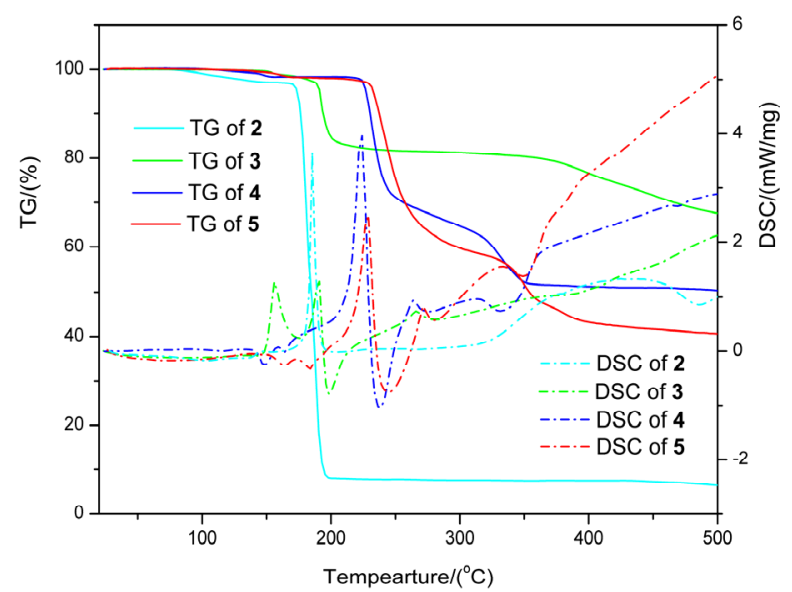

Figure 1. TG-DSC analysis of organobismuth complexes 2-5.

We first investigated the catalytic performance of $\mathbf{3}$ towards the direct three-component Mannich reaction of benzaldehyde, cyclohexanone and propylamine in ionic liquid $\left[\mathrm{Bmim}^{\mathrm{m}} \mathrm{BF}_{4}\right.$. However, a completely different product, $(E)-\alpha, \beta$-unsaturated ketone, was obtained. Since this process was efficient under mild conditions, we further evaluated the catalytic performance of 3 towards the synthesis of $\alpha, \beta$-unsaturated ketones. Furthermore, during the course of reaction, the nature of catalysis switches from homogeneous to heterogeneous (Figure 2). At the beginning, benzaldehyde 6a, cyclohexanone 7a, propylamine, complex $\mathbf{3}$ and $[\mathrm{Bmim}] \mathrm{BF}_{4}$ merge together and the reaction system is homogeneous (Figure 2(a)). By the end of the reaction, the system becomes turbid, and after 5 min of settling, the mixture separates into two phases. The upper consists of the product and unconsumed reactants while the lower consists of $[\mathrm{Bmim}] \mathrm{BF}_{4}$, complex 3, and water (the only side product) (Figure 2(b)). The findings were congruent to Leng groups work, which it has a catalytic procedure that is monophasic at the beginning and biphasic at the end. The overall reaction occurs at room temperature and there is no need to change any reaction condition. Previously, Leng's group deduced the system with such behavior and features as reaction- induced self-separation catalyst system, which is a facile separation catalyst system. The prominent feature of the system is its excellent solubility in water or polar solvents but immiscibility in apolar $\alpha, \beta$-unsaturated ketones. In other words, as a catalyst complex 3 dissolves completely in $[\mathrm{Bmim}] \mathrm{BF}_{4}$ as well as in the reactants, but is insoluble in the product $(\alpha, \beta$-unsatu- rated ketones). Thus at the early stage, the mixture for the cross-condensation reaction is homogeneous. With the consumption of reactants, the system becomes heterogeneous, and there is the spontaneous separation of the catalyst system (complex $\mathbf{3}$ and $\left.[\mathrm{Bmim}] \mathrm{BF}_{4}\right)$ and product. Eventually, the catalyst system can be easily recovered by simple decantation (Figure 2(c)). It is apparent that the advantages of both homogeneous and heterogeneous catalysis are captured in this method.

In a scale-up (x5) experiment, we found that catalyst loading can be lowered to $0.1 \mathrm{~mol} \%$ with the facile separation of catalyst system almost unaffected. Furthermore, the resulting ILs containing catalyst and water can be conveniently reused along with the unconsumed reactants and newly added substrates. Subject to desiccation treatment and owing to the air-stable, water-tolerant features and special interaction effect of the organobismuth complex and ILs $\left[\mathrm{Bmim}_{\mathrm{B}} \mathrm{BF}_{4}\right.$, the catalyst system can be recycled for at least ten times without significant decline in product yield (96-100\%) and stereoselectivity $(E / Z=100 / 0)$. Furthermore, we examined the structure integrity of the recycled catalyst (with $\left[\mathrm{Bmim}_{3} \mathrm{BF}_{4}\right.$ ) by the NMR technique and found that the structure of the recycled catalyst is consistent with that of the freshly prepared one. In other words, the catalyst is stable and suitable for reuse. It should be noted that the total substrate molar ratio $\left(\mathbf{6 a}: n-\mathrm{PrNH}_{2}: \mathbf{7 a}\right)$ for ten cycles is $1.0: 0.19: 1.2$, and the TON is up to 9893
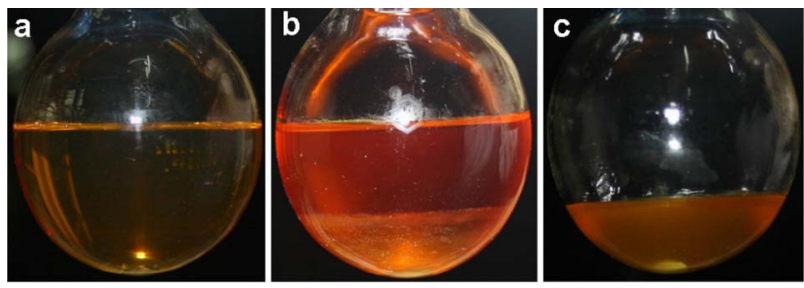

Figure 2. Photographs of the cross-condensation reaction of benzaldehyde 6a with cyclohexanone 7a over organobismuth complex 3 in the presence of propylamine in $\left[\mathrm{Bmim}_{\mathrm{B}} \mathrm{BF}_{4}\right.$. (a) Homogeneous mixture during reaction; $(b)$ the reaction system becomes heterogeneous at completion of reaction: the upper layer is composed of the product $(\alpha, \beta$-unsaturated ketones) and unconsumed reactants while the lower layer $[\mathrm{Bmim}] \mathrm{BF}_{4}$, complex 3 , and water generated in the reaction; (c) at the end of reaction, the layer of $\left[\mathrm{Bmim}^{-} \mathrm{BF}_{4}\right.$, catalyst 1 , and water was removed by decantation. 
Usually, a catalyst system is only conveniently suitable for certain substrates. However, the one depicted by us here can be applied to enolizable aliphatic aldehydes as well as to aromatic aldehydes with electron-donating and electron-withdrawing groups (Table 1. In all cases, the phenomenon of facile separation was observed with high product yields. Although the reaction of furfural occurs at $0^{\circ} \mathrm{C}$ (Table 1, entry 5), the $E$-selectivity for furfural is consistent with those of the other aldehydes. It is worth pointing out that the reaction of enolizable aliphatic aldehydes selectively produces $(E)-\alpha, \beta$-unsaturated ketones in almost quantitative yields without aldehyde facile condensation product or any-other side-product formation (Table 1, entries 6-7). On the other hand, the active methylene compounds appear to be efficient substrates in the present scheme (Table 1, entries 9-11). In all cases, no dibenzylidene byproduct is detected in NMR analysis. We ascribe such phenomenon to the special steric effect of monobenzylidene. In the catalyst system, it is hard for large group such as monobenzylidene to approach the active sites, and cross-condensation of monobenzylidene with cyclohexanone to form dibenzylidene byproduct is unlikely.

Due to the fact that complex 3 plays a major role in this facile separation catalyst system, we studied the crystal structure of $\mathbf{3}$ by X-ray analysis. An ORTEP representation of $\mathbf{3}$, and the selected bond lengths and angles are shown in Figure 3. It is clear that the organobismuth component in $\mathbf{3}$ is cationic. The oxygen atom of the coordinating water occupies a vacant site of the cationic bismuth centre, making the coordination geometry distorted and equatorially vacant. One can see a trigonal bipyramidal with the sulfur and the oxygen atoms in the apical positions and the two carbon atoms in the equatorial positions.

Table 1. Synthesis of different $\alpha, \beta$-unsaturated ketones catalyzed by cationic organobismuth complex 3 in $[\mathrm{Bmim}] \mathrm{BF}_{4}{ }^{a}$

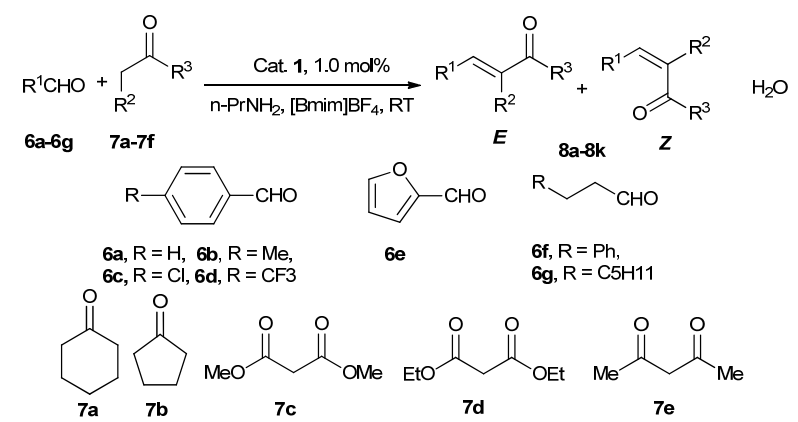

\begin{tabular}{cccccc}
\hline Entry & $\mathbf{R}^{\mathbf{1}} \mathbf{C H O}$ & Ketone & Product & Yield (\%) $^{\mathbf{b}}$ & $\mathbf{E} / \mathbf{Z c}$ \\
\hline 1 & $\mathbf{6 a}$ & $\mathbf{7 a}$ & $\mathbf{8 a}$ & 98 & $100 / 0$ \\
2 & $\mathbf{6 b}$ & $\mathbf{7 a}$ & $\mathbf{8 b}$ & 93 & $100 / 0$ \\
3 & $\mathbf{6 c}$ & $\mathbf{7 a}$ & $\mathbf{8 c}$ & 99 & $100 / 0$ \\
4 & $\mathbf{6 d}$ & $\mathbf{7 a}$ & $\mathbf{8 d}$ & 100 & $100 / 0$ \\
$5 \mathrm{~d}$ & $\mathbf{6 e}$ & $\mathbf{7 a}$ & $\mathbf{8 e}$ & 98 & $100 / 0$ \\
6 & $\mathbf{6 f}$ & $\mathbf{7 a}$ & $\mathbf{8 f}$ & 100 & $100 / 0$ \\
7 & $\mathbf{6 g}$ & $\mathbf{7 a}$ & $\mathbf{8 g}$ & 98 & $100 / 0$ \\
8 & $\mathbf{6 a}$ & $\mathbf{7 b}$ & $\mathbf{8 h}$ & 97 & - \\
9 & $\mathbf{6 a}$ & $\mathbf{7 c}$ & $\mathbf{8 i}$ & 99 & - \\
10 & $\mathbf{6 a}$ & $\mathbf{7 d}$ & $\mathbf{8 j}$ & 98 & - \\
11 & $\mathbf{6 a}$ & $\mathbf{7 e}$ & $\mathbf{8 k}$ & 95 & -- \\
\hline
\end{tabular}

a6, $20 \mathrm{mmol}$; $\mathrm{n}-\mathrm{PrNH}_{2}, 20 \mathrm{mmol}$; 7, $60 \mathrm{mmol}$; 3, $0.2 \mathrm{mmol}$; [Bmim $] \mathrm{BF}_{4}, 1.0 \mathrm{~mL}$; RT. ' Isolated yield. ${ }^{\mathrm{c}}$ Determined by $1 \mathrm{H}$ NMR. ${ }^{\mathrm{d}} 0 \mathrm{oC}$.
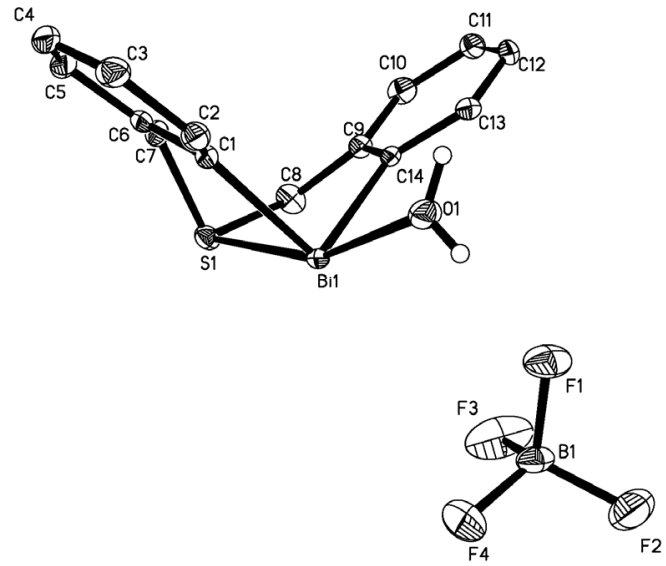

Figure 3. An ORTEP view (30\% probability level) of 3 . Selected bond lengths $(\AA)$ and angles (deg): $\mathrm{Bi}(1)-\mathrm{C}(1), 2.256(7)$; $\mathrm{Bi}(1)-\mathrm{C}$ (14), 2.262(7); Bi(1)-O(1), 2.499(6); Bi(1)-S(1), 2.6992(19); S(1)-C(7), 1.815(8); S(1)-C(8), 1.816(9); O(1)-H(1A), 0.8180; O(1)-H(1B), 0.7499; C(1)-Bi(1)-C(14), 97.2(2); C(1)-Bi(1)-O(1), 86.3(2); C(14)Bi(1)-O(1), 90.7(2); C(1)-Bi(1)-S(1), 78.01(19); C(14)-Bi(1)-S(1), 78.01(19); O(1)-Bi(1)-S(1), 159.20(14); C(7)-S(1)-C(8), 101.0(4); $\mathrm{C}(7)-\mathrm{S}(1)-\mathrm{Bi}(1), 95.7(3) ; \mathrm{C}(8)-\mathrm{S}(1)-\mathrm{Bi}(1), 94.7(3) ; \mathrm{Bi}(1)-\mathrm{O}(1)-$ $\mathrm{H}(1 \mathrm{~A}), 109.5 ; \mathrm{Bi}(1)-\mathrm{O}(1)-\mathrm{H}(1 \mathrm{~B}), 119.8$.

The Bi-S(1) distance (2.699(19)) is shorter than that (2.845 $\AA$ ) of precursor 1, clearly suggesting stronger sulfur-to-bismuth coordination in 3. The $\mathrm{Bi}-\mathrm{O}(1)$ distance $(2.499(6)$ for 3 ) is longer than that of covalent $\mathrm{Bi}-\mathrm{O}$ bonds (e.g., $\mathrm{Bi}-\mathrm{O}$ bond distances of monomeric diorganobismuth alkoxides within 2.15-2.20 $\AA$ ), indicating that the weakly coordinated water molecule can be replaced by a substrate. The dihedral angle of the two phenyl planes (ca. 107 degrees) is equal to the $\mathrm{C}(1)-\mathrm{Bi}-\mathrm{C}(14)$ angle (97.2 degrees) and the $\mathrm{C}(7)-\mathrm{S}(1)-\mathrm{C}(8)$ angle (101 degrees). This butterfly-shaped cationic organobismuth ion is similar to that of 1,1'-binaphthol template used as asymmetric catalyst in organic synthesis.

Although further study is necessary to clarify the reaction mechanism, the results mentioned so far suggest that the reaction probably takes place through a Mannich-type mechanism as shown in Scheme 3. In the reaction, the complex with the above framework displays Lewis acidic/basic bifunctional properties with the accessible bismuth centers acting as a Lewis acid sites and the uncoordinated lone-pair electrons of sulfur as Lewis base sites. However, it should be noted that when organobismuth complex $\mathbf{3}$ is used as catalyst in the presence of propylamine in ILs, high catalytic activity was observed in cross-condensation of benzaldehyde and cyclohexanone, displaying high synthetic yield and diastereoselectivity (yield $98 \%$, $E / Z=100 / 0)$. Very different result is obtained when water is used as solvent (yield $94 \%, E / Z=90 / 10$ ), suggesting that the ILs play an important role in the control of diastereoselectivity. We utilized NMR technique to investigate the interaction of complex 1 with $\left[\mathrm{Bmim} \mathrm{BF}_{4}\right.$ (Scheme 4).

Because of interaction such as hydrogen bonding and the special phenyl planar geometry, we postulate that the ${ }^{1} \mathrm{H}$ NMR singlet of water molecules or ILs coordinated with the Bi catalyst should shift to high field. The change of ${ }^{1} \mathrm{H}$ NMR chemical shift that is related to methyl and methylene group linked to the nitrogen atom of $[\mathrm{Bmim}] \mathrm{BF}_{4}$ is consistent with our hypothesis, 


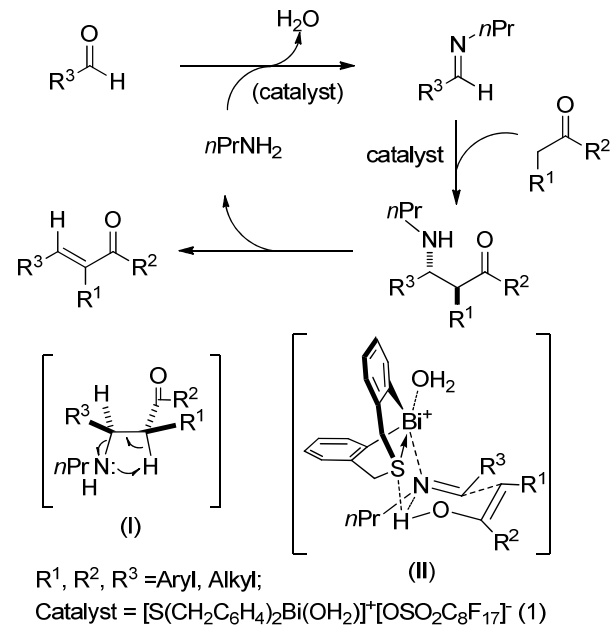

Scheme 3. A plausible catalytic cycle for the crossed-condensation reaction of ketones and aldehydes catalyzed by 3 in the presence of $n$-PrNH .

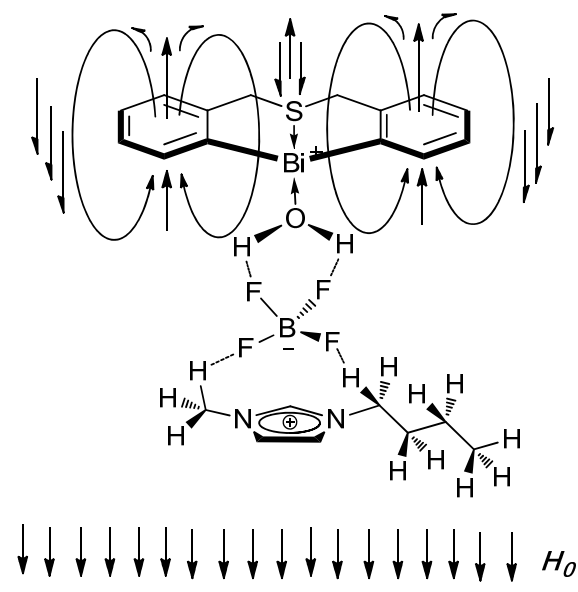

Scheme 4 Proposed interaction of complex 3 and imidazolium cationic ion $[\mathrm{Bmim}]^{+}$in ionic liquids.

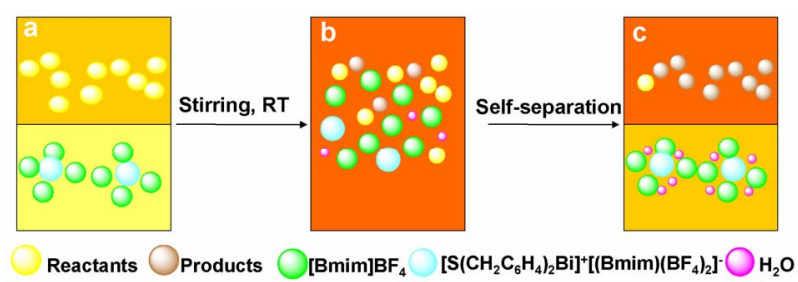

Figure 3. Interaction of catalyst 3 with $[\mathrm{Bmim}] \mathrm{BF}_{4}$ in the catalyst system. (a) The upper layer contains reactants benzaldehyde, cyclohexanone, and propylamine while the lower layer ILs and catalyst 3. (b) Homogeneous mixture during reaction. (c) Heterogeneous mixture at completion of reaction; the upper layer is $\alpha, \beta$-unsaturated ketones and unconsumed reactants while the lower layer ILs, catalyst 1 , and water generated during reaction.

implying that hydrogen bonding is apparent. With hydrogen bond formation, there should be enhancement of electronwithdrawing ability, consequently enhancing the diastereoselectivity of the reaction (Figure 4). Furthermore, the adduct formed from the Bi complex and ILs leads to miscibility of the catalyst in the ILs. The water generated is absorbed by the hydrophilic ILs, inducing stronger polarity of ILs that is beneficial for the facile separation process. With the consumption of reactants and the generation of apolar $\alpha, \beta$-unsaturated ketones, facile separation of products from the polar solution occurs. In other words, the product can be transferred to the apolar organic phase directly and efficiently, breaking the equilibrium of cross-condensation reaction in a controlled manner.

\section{Conclusion}

We have developed a facile separation catalyst system (composed of [Bmim $] \mathrm{BF}_{4}$ and air-stable organobismuth tetrafluoroborate 1) that is highly efficient (showing high catalytic activity, stereoselectivity, stability, and reusability) for the synthesis of $(E)$ $\alpha, \beta$-unsaturated ketones from aldehydes and ketones through direct crossed-condensation.

\section{Acknowledgements}

This work was financially supported by the NSFC (Grant Nos. 20973056, 21003040, 20873038 and E50725825), and the 863 project (2009AA05Z319). Prof. C.-T. Au (adjunct professor of Hunan University) and Prof. W.-Y. Wong thank the Hong Kong Baptist University for a Faculty Research Grant (FRG/ 08-09/II-09). Prof. Yin thanks Dr. S. Shimada of AIST in Japan for helpful advice.

\section{REFERENCES}

[1] S. Yin, J. Maruyama, T. Yamashita, S. Shimada, "Efficient fixation of carbon dioxide by hypervalent organobismuth oxide, hydroxide, and alkoxide," Angew. Chem. -Int. Ed., vol. 47, pp. 6590-6593, 2008

[2] S.-F. Yin, S. Shimada, "Synthesis and structure of bismuth compounds bearing a sulfur-bridged bis(phenolato) ligand and their catalytic application to the solvent-free synthesis of propylene carbonate from $\mathrm{CO}_{2}$ and propylene oxide," Chem. Commun., pp. 1136-1138, 2009

[3] R. Qiu, Y. Qiu, S. Yin, X. Song, Z. Meng, X. Xu, X. Zhang, S. Luo, C.-T. Au, W.-Y. Wong, "Facile separation catalyst system: direct diastereoselective synthesis of $(E)-\alpha, \beta$-unsaturated ketones catalyzed by an air-stable Lewis acidic/basic bifunctional organobismuth complex in ionic liquids," Green Chem., vol. 12, pp.1767-1771, 2010.

[4] R. Qiu, Y. Qiu, S. Yin, S. Luo, C.-T. Au, W.-Y. Wong, S. Shimada, "Highly Efficient and Selective Synthesis of $(E)-\alpha$, $\beta$-Unsaturated Ketones by Crossed Condensation of Ketones and Aldehydes Catalyzed by an Air-Stable Cationic Organobismuth Perfluorooctanesulfonate," Adv. Synth. Catal., vol. 352, pp. $153-162,2010$

[5] R. Qiu, S. Yin, X. Song, Z. Meng, Y. Qiu, N. Tan, X. Xu, X. Zhang, S. Luo, F.-R. Dai, C.-T. Au, W.-Y. Wong, "Effect of butterfly-shaped sulfur-bridged ligand and counter anions on the catalytic activity and diastereoselectivity of organobismuth complexes," Dalton Trans., vol. 40, pp. 9482-9489, 2011

[6] R. Qiu, S. Yin, X. Zhang, J. Xia, X. Xu, S. Luo, "Synthesis and structure of an air-stable cationic organobismuth complex and its use as a highly efficient catalyst for the direct diastereoselective Mannich reaction in water," Chem. Commun., pp. 4759-4761, 2009 